American Journal of Agricultural and Biological Sciences 4 (3): 206-214, 2009

ISSN 1557-4989

(C) 2009 Science Publications

\title{
Analyzing the Effects of Water and Agriculture Policy Strategies: An Iranian experience
}

\author{
${ }^{1}$ Reza Moghaddasi, ${ }^{1}$ Ali Bakhshi and ${ }^{2}$ Mahmood Daneshvar Kakhki \\ ${ }^{1}$ Department of Agricultural Economics, Science and Research Branch, \\ Islamic Azad University, Tehran, Iran \\ ${ }^{2}$ Department of Agricultural Economics, Ferdowsi University of Mashhad, Iran
}

\begin{abstract}
Problem statement: Because of growing demand for water resources, increasing cost of supplying water and overdraft of underground waters, economists suggest water pricing policy to improve water allocation efficiency in Iran. While due to political risk, economic and cultural concerns, government tends to reject that advice. This study addressed questions of what policy alternatives to water pricing could be used to improve irrigation water allocation efficiency. Approach: Three policy options include water pricing, water complementary input factor taxes and output taxes were examined. In order to minimize the problems of bias produced by fully aggregated models, sample farms were classified into homogeneous groups of farmers by means of clustering technique. The analysis carried out by means of Positive Mathematical Programming (PMP), utilizing quadratic cost functions. Results: Results showed that effects of alternative policies were strongly dependent on group of farmers and that would create widespread effects on policy goals across clusters. The results also indicated that water pricing policy worked well in reducing the irrigation water use when the water price level was high and will have, in most cases, higher effects than other policy scenarios. Conclusion: Low level of input taxation wasn't a good driver in decreasing irrigation water demand and keeping the welfare level. Water pricing and output tax policies were better suited and effective than water complementary input factor taxation but both input factor tax and output tax policy at certain rates could be alternatives to water pricing policy. Water pricing policy had noticeable effects on social and environmental goals, while input and output taxes had small effects on that goals.
\end{abstract}

Key words: Water pricing, cluster analysis, PMP, CES production function

\section{INTRODUCTION}

Water scarcity and its impacts on agricultural production and food security are growing concerns worldwide. Increasingly, water scarcity is described as a major challenge facing Iran, an arid and semiarid country, with an average annual precipitation $(250 \mathrm{~mm})$ which is less than one-third of the world average. In Iran, irrigated agriculture is responsible for $89 \%$ of agricultural production, with only $52 \%$ of the cultivated area -6.7 million ha-consuming $90 \%$ of the total water supply ${ }^{[20]}$. Overdraft of groundwater resources has caused negative balance of groundwater and out of 612 plains of the country, 150 plains are restricted. At present, pricing irrigation water is based on the so called equitable distribution law of 1988. According to this law, surface water charges are based on some percentage of the value of output (output pricing). Since this system of pricing is not based on the volume of water delivered, it lacks the incentive for efficient use of irrigation water. In the case of groundwater resources, price is between $0.25-1.0 \%$ of the commercial value of crop yield. Irrigation water in Iran is heavily subsidized. It has been estimated that, water charges in public irrigation schemes only cover $12 \%$ of the supply $\operatorname{cost}^{[4]}$. Limitations of development water resources, apparently poor management and large losses of water in Iranian irrigated areas compel the implementation of demand water policies. Such demand policies consist in the main of the public reallocation of water resources, water pricing and alternative irrigation policies such as water complementary input factor taxes and output taxes ${ }^{[6,11]}$.

Using empirical evidence from Iran to assess the effectiveness of water pricing in curtailing demand, Perry ${ }^{[2,13,17,23]}$ have estimated a $10,3.5,3$ and 10 fold increase for irrigation water prices in different regions, respectively. It concerns the low farmer responsiveness

Corresponding Author: Ali Bakhshi, Department of Agricultural Economics, Science and Research Branch, Islamic Azad University, Tehran, Iran 
Am. J. Agri. \& Biol. Sci., 4 (3): 206-214, 2009

at observed prices ranges. Therefore agricultural water prices need to be raised significantly or introducing alternative irrigation policies. The implementation of these economic instruments would produce collateral effects, such as a decrease in agricultural income and a reduction in the demand for agricultural labor. The solution to get rid of water scarcity is to improve water allocation and concentrate on the integrated water and land management, emphasizing on the agricultural water management ${ }^{[8,23]}$. The objectives of this research are to evaluate alternative policy options to see if and how well they can serve as a proxy of water pricing policy in study area and to analyze the potential impacts on cropping pattern, irrigation water demand, welfare, labor employment and environment for each alternative strategic policy. In sum, knowing the farmers response to these new policies will indeed illuminate the decision making process of policy choice to attain the desired goals of reducing water demand and alleviating water scarcity.

\section{MATERIALS AND METHODS}

The methodology is intended to simulate the impact of alternative water policy scenarios, based on the following steps: (1) representative farms (RFs); (2) The Model; (3) Definition of water policy scenarios; (4) simulation of responses.

Representative farms: As the economic and social characteristics of farms, vary from farm to farm within region, the same policy instruments can lead to extremely different results. Consequently, policymakers need to preliminarily know the effects that the new policies can induce on the homogeneous groups of farmers. The aim is to identify farms with homogeneous characteristics with respect to the production activities, to the resources usage and to the economic features of study area. The cluster analysis was intended to gather farms within relatively homogeneous groups in order to account for heterogeneity between groups of farms ${ }^{[7,9]}$. To construct the PMP models, a random sample of 172 farmers was selected from the Mashhad plain in Khorasan province of Iran. Data were obtained from sample farmers by way of structured questionnaire and personal interviews. It is necessary to assess the relevance of the variables to the problem being investigated and use the factor analysis to remove highly correlated variables ${ }^{[1]}$. In the next stage, to avoid aggregation bias, we used classification variables for any individual farm (net income and resource use per hectare, endowment of different resources) which were acquired from previous
Table 1: Basic data per representative farm

\begin{tabular}{|c|c|c|c|c|c|}
\hline \multirow[b]{2}{*}{ Characteristics } & \multicolumn{4}{|c|}{ Cluster number } & \multirow[b]{2}{*}{ Averag } \\
\hline & 1 & 2 & 3 & 4 & \\
\hline Area (ha) & 485.0 & 2349.0 & 369.00 & 276.0 & - \\
\hline No. of farms & 35.0 & 63.0 & 37.00 & 21.0 & - \\
\hline $\begin{array}{l}\text { Average farm } \\
\text { size (ha) }\end{array}$ & 13.9 & 37.3 & 10.00 & 13.1 & 18.6 \\
\hline $\begin{array}{l}\text { Gross margin } \\
\left(10^{6} \text { Rials* }^{*} \mathrm{ha}^{-1}\right)\end{array}$ & 6.5 & 19.6 & 21.10 & 12.2 & 14.8 \\
\hline $\begin{array}{l}\text { Land/labor ratio } \\
\text { (ha man-day }^{-1} \text { ) }\end{array}$ & 1.49 & 0.35 & 0.06 & 0.10 & 0.5 \\
\hline $\begin{array}{l}\text { Irrigation water } \\
\left(\mathrm{m}^{3} \mathrm{ha}^{-1}\right)\end{array}$ & 5096.00 & 4429.0 & 5761.00 & 4663.00 & - \\
\hline $\begin{array}{l}\text { Price of water } \\
\left(\text { Rials m }{ }^{-3}\right)\end{array}$ & 217.00 & 296.0 & 336.00 & 629.00 & 369.0 \\
\hline
\end{tabular}

stage to construct RFs. Considering classification variables reveals that these variables almost conform with Day's aggregation conditions ${ }^{[7]}$. RFs were selected on the basis of Hierarchical cluster analysis and clustering was performed using the Ward's minimum variance criterion as the clustering method and squared Euclidean distance as measure. The hierarchical tree (dendrogram) showed the appropriate number of clusters for this sample as four. The main descriptive statistics for each cluster are shown in Table 1.

The farms in cluster 2 with an average farm size of 37.3 ha, are larger than other farms while farms in cluster 3 have smallest size with an average farm size 13.1 ha. Both clusters 2 and 3 include farms with the highest Gross margin per hectare, but cluster 3 consists of 37 farms with lower acreage and cluster 2 consists of 63 farms with highest acreage. Farms in clusters 3 and 4 also have on average the smallest land/labor ratio, compared to farms from the other two clusters. It is likely that these farms have a larger number of labors per hectare and so called, production process in these farms compared to farms from clusters 1 and 2 is labor intensive. Comparing total available irrigation water and total acreage per cluster indicates that on average, farms in the first and the third clusters use higher rates of water per hectare than the first and the second groups of farms. In other words, first and the third groups of farmers planted water-intensive crops and two other groups grow crops with low water requirement. For each group of farmers price of water and water consumption per hectare has similar behavior, so that from first to fourth cluster price of water and water consumption per hectare increases.

Model: The study uses an extended version of the standard PMP model calibration approach ${ }^{[14]}$. Once homogeneous groups of farmers (clusters, or RFs), have been defined, the second stage builds the mathematical 
models. The modeling analyses will be presented, based on results of four models, developed for sample farms. In order to allow independent simulations based on the decision-making behavior of the various groups of farmers to be run, each cluster has been modeled separately. For this purpose, the basic elements of any mathematical model; i.e., decision variables, objective function and set of constraints, have to be outlined. The PMP calibration method adopted in this model utilises a non-linear cost function and a CES production function for each production activity. The value of each variable per cluster is an average of individual farms included in that cluster. Since the publication of a comprehensive study on PMP in agricultural policy models by Howitt ${ }^{[14]}$, this calibration approach has become a standard methodology and has been employed in various models at farm $^{[5,16]}$, regional $^{[3,10,18,22]}$ ) and sector level ${ }^{[19]}$. A farm level and multi-crop program is proposed for this study following Howitt ${ }^{[14,15]}$. The approach adopted can be divided into three different stages: (1) The construction of a usual linear program model with calibration constraints, (2) The use of the resulting dual values to calibrate the parameters of the nonlinear objective function (3) The simulation of agricultural policy changes. In stage (1), we consider the following Linear Program (LP):

$$
\max \quad Z=\sum_{i} p_{i} \bar{y}_{i} x_{i}-\sum_{j} \omega_{j} a_{i j} x_{i}
$$

Subject to:

$$
\begin{aligned}
& \mathrm{Ax} \leq \mathrm{b} \quad\left[\lambda_{1}\right] \\
& \mathrm{x} \leq \mathrm{x}_{0}+\varepsilon \quad\left[\lambda_{2}\right] \\
& \mathrm{x} \geq 0
\end{aligned}
$$

$\mathrm{Z} \quad=$ the objective function value

P and $\omega=$ Represent the price per unit for output $i$ and accounting costs per unit of input $j$, respectively

$\mathrm{x}=$ the non-negative vector of surface cultivated with production $\mathrm{i}$

$\overline{\mathrm{y}}_{\mathrm{i}} \quad=$ Indicates the production yield in the reference year

Equation 2 and 3 denote the resource constraints and calibration constraints, respectively. A is matrix of technical coefficients in resource constraints with $a_{i j}$ elements. $b$ shows the vector of available resource levels and $\mathrm{x}_{0}$ is non-negative vector of observed activity levels. $\varepsilon$ represents the vector of small positive numbers for preventing linear dependency between the structural constraints and the calibration constraints. In addition to dual values for the limiting allocable resources $\left(\lambda_{1}\right)$, this constrained program generates dual values $\left(\lambda_{2}\right)$ for each activity except for the marginal activity.

In the first stage, calibration constraints are added to the initial base-year linear program to, binding the activities to the observed levels of the baseline. Howitt $^{[14]}$ and Paris and Howitt ${ }^{[21]}$ interpret the dual variable vector $\lambda_{2}$, associated with the calibration constraints as capturing any type of model misspecification, data errors, aggregate bias, risk behavior and price expectations. Graindorge et al. ${ }^{[10]}$ attributed dual variable vector $\lambda_{2}$ to heterogeneous land or livestock quality. In the perspective of calibrating a non-linear decreasing yield function as in Howitt ${ }^{[14]}$, this $\lambda_{2}$ represents the difference between the activity average and marginal value products. In the alternative perspective of calibrating a non-linear increasing cost function as in Paris and Howitt ${ }^{[21]}$, this dual vector $\lambda_{2}$ is interpreted as a differential marginal cost vector that together with the activity accounting cost vector $\omega$ reveals the actual variable marginal cost of supplying the observed activity vector $x_{0}$.

In the second stage, marginal values (dual values) from the previous stage are used along with the baseyear data set to calculate parameters needed by a quadratic cost function and a CES production function. These functions together form a nonlinear program that produces the base year solution without calibration constrains. In this stage the dual values calibrate the parameters of the nonlinear objective function. For reasons of computational simplicity and lacking strong arguments for other type of functions a quadratic cost function is usually employed in the objective function $^{[12]}$. However any type of nonlinear function with the required properties is acceptable to this step. The general version of this variable cost function for each crop, as quadratic in the acreage allocated to the crop, to be specified is:

$$
C^{\mathrm{v}}=\mathrm{d}^{\prime} \mathrm{x}+\frac{1}{2} \mathrm{x}^{\prime} \mathrm{Qx}
$$

Where:

$\mathrm{d}=$ Denotes vector of parameters associated with the linear term

$\mathrm{Q}=\mathrm{A}$ symmetric, positive semi definite matrix of parameters associated with the quadratic term

The parameters are then specified so that the linear marginal variable cost functions $\left(\mathrm{MC}^{\mathrm{v}}\right)$ for different crops fulfill: 


$$
\mathrm{MC}^{\mathrm{v}}=\frac{\partial \mathrm{C}^{\mathrm{v}}\left(\mathrm{x}^{0}\right)}{\partial \mathrm{x}}=\mathrm{d}+\mathrm{Qx}^{0}=\omega+\lambda_{2}
$$

To solve this system of $\mathrm{n}$ equation for $\mathrm{n}$ crop, PMP modelers rely on various solutions. Judez et al. ${ }^{[16]}$ directly derived the unknown parameters of the final non-linear model from the Kuhn-Tucker conditions. Paris and Howitt ${ }^{[21]}$ exploited the maximum entropy estimator to determine all elements of the vector $d$ and matrix Q using the Cholesky factorization while, Paris $^{[22]}$ generalized the PMP framework into a Symmetric Positive Equilibrium Problem. Among them, the average cost approach used in this study which equates the accounting cost vector $\omega$ to the average cost vector of the quadratic cost function and leads to:

$$
\mathrm{q}_{\mathrm{ii}}=2 \lambda_{2} / \mathrm{x}_{0} \text { and } \mathrm{d}_{\mathrm{i}}=\omega_{\mathrm{i}}-\lambda_{2} \text { for all } \mathrm{i}=1, \ldots \mathrm{n}
$$

where, $\mathrm{q}_{\mathrm{ii}}$ denote the $\mathrm{n}$ diagonal elements of matrix $\mathrm{Q}$. By using the prior information, technology is represented by a CES production function, which allows input substitution among production factors. The CES production function is usually written as:

$$
\mathrm{y}=\alpha\left(\sum_{\mathrm{j}=1}^{\mathrm{n}} \beta_{\mathrm{j}} \cdot \mathrm{X}_{\mathrm{j}}^{\gamma}\right)^{1 / \gamma}
$$

Where:

$\mathrm{y}=$ An output

$\mathrm{X}_{\mathrm{j}}=$ An input

$\alpha=$ Scale (yield) parameter

$\beta_{\mathrm{j}}=$ Share parameter

The CES share and scale parameters are estimated according to Howitt ${ }^{[15]}$ by using the first-order conditions for input allocation. Details of estimation appear in Howitt ${ }^{15]}$. The substitution parameter $\gamma$ is related to the elasticity of substitution $\sigma$ by the relation $\sigma=1 /(1-\gamma)$. Where $\gamma=(\sigma-1) / \sigma, \sum \beta_{\mathrm{j}}=1$ and $\sigma$ is prior value elasticity of substitution. The elasticity of input substitution coefficient of the CES function (Eq. 8) is derived from empirical sources. In the third stage, the derived cost parameters and the base-year data set are used to specify a non-linear program that includes the original constraints except the calibration constraints. Formally, the calibration stages lead to the following model structure adapted from Howitt ${ }^{[14]}$ :

$$
\max \pi=p^{\prime} y-d^{\prime} x-x^{\prime} Q x / 2
$$

Subject to: $y=f(x)$

$$
\mathrm{Ax} \leq \mathrm{b} \quad\left[\lambda_{1}\right]
$$

$\mathrm{x} \geq 0$

Equation 9 maximizes Total Net Revenue (TNI) corresponds to a farm group, while Eq. 11 and 12 are constraint sets for production factors. The first term in Eq. 9 shows the total revenue and the two last terms in Eq. 9 form a quadratic cost function. This calibrated model can be used for policy change simulations. The models were solved and developed using solver MINOS, run over GAMS as the optimization software.

Definition of water policy scenarios: In order to simulate the impacts of various policy scenarios we employed water price, input and output policies related to water use. As indicated in Table 2, three policy scenarios were simulated using PMP models: (1) Water pricing policy; (2) An input tax policy; and (3) An output tax policy. Each scenario has multiple subscenarios. The water pricing scenario observes the effects under different irrigation water pricing levels. The first price level (W1) is $100 \%$ increase in current water price. The second and third price levels (W2 and W3) are $100 \%$ increase in water price levels plus changing the irrigation water constraint to less than the binding level by 10 and 20\%, respectively. Changing price of nitrogen fertilizer ( $\mathrm{N}$-fertilizer) and fungicide affects on crop production costs and consequently changes welfare, irrigation water demand and cropping patterns. The tax rates for these resources are at 25 (I1) and 50\% (I2). The output tax scenario taxes sugar beet and tomato production since these crops are irrigation water intensive among all other crops in study area. An output tax is a price cut on the producer side at $10(\mathrm{O} 1)$ and $20 \%(\mathrm{O} 2)$ which could take the form of reducing the subsidies on corresponding crops.

The models were developed in order to derive the results of the policy simulation which are presented in four categories:

Economic impacts: are measured by percentage change in TNI.

Water conservation: The projected consumption of water measured in $\mathrm{m}^{3} \mathrm{ha}^{-1}$, is the variable that policy makers wish to control via different policy options. Water conservation is measured by the decreasing rate of demand for irrigation water after implementing a certain policy. 
Table 2: Description of policy scenarios in Mashhad plain

\begin{tabular}{|c|c|c|c|c|c|c|c|}
\hline \multirow{2}{*}{$\begin{array}{l}\text { Scenarios } \\
\text { Sub-scenarios }\end{array}$} & \multicolumn{3}{|c|}{ Water pricing policy } & \multirow{2}{*}{\multicolumn{2}{|c|}{$\begin{array}{l}\text { Input tax policy } \\
\text { n-fertilizer Fungicide }\end{array}$}} & \multicolumn{2}{|c|}{ Output tax policy } \\
\hline & $\mathrm{Wl}$ & W2 & W3 & & & Sugar beet & Tomato \\
\hline $\begin{array}{l}\text { Water pricing } \\
\text { Input tax } \\
\text { Output tax }\end{array}$ & * & * & * & $*$ & * & $*$ & $*$ \\
\hline
\end{tabular}

Land reallocation: Variation in level of activities is measured as an indicator of reallocating land input to different crops in response to enforced policies.

Social impact: irrigated agriculture is the main source of employment in study area. We expect that changes in policy rules could affect the social structure of this region. This phenomenon can be evaluated via changes in agricultural Labor use.

Environmental impact: An environmental effect of growing relevance is the pollution caused by the use of agrochemicals in agriculture. The percentage change in consumption of $\mathrm{N}$-fertilizer and fungicide are taken as indicators of the environmental impact of agricultural activities that caused by the policy options.

Area of study: The practical application of the methodology proposed above is based on the community of irrigators of the Mashhad plain in Northeast of Iran. The climate in the area is typically dry with an annual average precipitation of $203 \mathrm{~mm}$. In this area, agriculture faced with over-exploitation and critical conditions of groundwater aquifers so that there is a difference of $1.06 \mathrm{bcm}$ between recharge of water resources $(8.6 \mathrm{bcm})$ and discharges from them $(9.66 \mathrm{bcm})$ in Mashhad plain.

\section{RESULTS}

This section analyses the results obtained from solving PMP models simulating alternative scenarios. Model runs for each RF and policy alternative were performed by using GAMS as the optimization software. Results include water conservation, land reallocation, economic, social and environmental impacts.
Economic impact: The percentage change in welfare from its base level is reported in Table 3. Results from policy scenarios simulation indicate that water pricing policy scenarios have the greatest negative impact on TNI of RFs. while input tax policies function at the opposite state and have a negligible negative effect on TNI. The fall in total welfare ranges between 0 and $55 \%$ of the current TNI, depending on the cluster. A reduction in welfare is the lowest with the cluster 2 , i.e., the farms with highest farm size and the lowest Irrigation water consumption per hectare. Alternative policies, especially water pricing policies, had significantly decreased welfare level related to $4^{\text {th }} \mathrm{RF}$. Since Farms in 4th RF experience the highest water price, there is a slight difference between current and shadow water price with this group of farms. The results show that change in welfare vary across RFs and alternative policies so that different pricing policies produce clear differential effects on the irrigation farms of study area. W2 and W3 policies have larger effects on welfare than W1 policy. Input tax policy has small effects than water pricing and output tax policy scenarios on farmers' total welfare. Both input and output tax policies have inappreciable effect at farm level. $\mathrm{N}$-fertilizer tax affects crop production costs and therefore production decisions. However, until the tax rate of $\mathrm{N}$-fertilizer increases by more than $50 \%$ we do not see appreciable changes in reduction of welfare.

In the fungicide tax scenario, changing the fungicide cost has limited effects on the welfare level. When fungicide costs increase $50 \%$, the welfare level decreases by less than $0.1 \%$ (ranges between 0 and $0.07 \%)$. Twenty five percent of output tax (O1) will decrease level of welfare more than the I1 and I2 level, while output tax at $50 \%(\mathrm{O} 2)$ decreased more welfare than O1. It is necessary to emphasize that the effect on farmers' welfare would be quite different in the four clusters considered. This decrease in the profitability of irrigated agriculture, especially as a result of water pricing interventions, might well lead in to the withdrawal of a large percentage of farmers from agriculture.

Table 3: Reductions in total welfare (\%)

\begin{tabular}{|c|c|c|c|c|c|c|c|c|c|c|c|}
\hline \multirow[b]{3}{*}{ Model No. } & & & & \multicolumn{4}{|c|}{ Input tax policy } & \multicolumn{4}{|c|}{ Output tax policy } \\
\hline & \multicolumn{3}{|c|}{ Water pricing policy } & \multicolumn{2}{|c|}{$\mathrm{n}$-fertilizer } & \multicolumn{2}{|c|}{ Fungicide } & \multicolumn{2}{|c|}{ Sugar beet } & \multicolumn{2}{|c|}{ Tomato } \\
\hline & . Wl & W2 & W3 & I1 & $\mathrm{I} 2$ & I1 & $\mathrm{I} 2$ & $\mathrm{O} 1$ & $\mathrm{O} 2$ & $\mathrm{O} 1$ & $\mathrm{O} 2$ \\
\hline$\overline{(1)}$ & 7.1 & 11.8 & 11.8 & 0.01 & 0.04 & 0.02 & 0.07 & 0.60 & 0.80 & 1.13 & 1.13 \\
\hline (2) & 5.8 & 11.0 & 11.0 & 0.04 & 0.11 & 0.01 & 0.02 & 0.06 & 0.06 & 2.40 & 4.40 \\
\hline (3) & 6.5 & 12.5 & 12.5 & 0.01 & 0.02 & 0.02 & 0.04 & 2.70 & 5.00 & 5.00 & 9.00 \\
\hline (4) & 28.0 & 53.0 & 55.0 & 0.10 & 0.30 & 0.00 & 0.00 & 3.80 & 10.00 & 2.00 & 1.50 \\
\hline
\end{tabular}


Am. J. Agri. \& Biol. Sci., 4 (3): 206-214, 2009

Table 4: Water conservation in different scenarios (\%)

\begin{tabular}{|c|c|c|c|c|c|c|c|c|c|c|c|}
\hline \multirow[b]{3}{*}{ Model No. } & & & & \multicolumn{4}{|c|}{ Input tax policy } & \multicolumn{4}{|c|}{ Output tax policy } \\
\hline & \multicolumn{3}{|c|}{ Water pricing policy } & \multicolumn{2}{|c|}{ n-fertilizer } & \multicolumn{2}{|c|}{ Fungicide } & \multicolumn{2}{|c|}{ Sugar beet } & \multicolumn{2}{|c|}{ Tomato } \\
\hline & Wl & W2 & W3 & $\mathrm{I} 1$ & $\mathrm{I} 2$ & I1 & $\mathrm{I} 2$ & $\mathrm{O} 1$ & $\mathrm{O} 2$ & $\mathrm{O} 1$ & $\mathrm{O} 2$ \\
\hline (1) & 330 & 64.0 & 64.0 & - & - & - & - & - & 16.4 & - & - \\
\hline (2) & 240 & 34.0 & 34.0 & 4.0 & 4.0 & 3.90 & 4.00 & 13 & 13.0 & 2.4 & 2.4 \\
\hline (3) & 8.8 & 17.6 & 19.7 & 0.2 & 0.2 & 0.18 & 0.18 & 5 & 9.0 & 2.9 & 5.0 \\
\hline (4) & - & 8.0 & 16.0 & - & - & - & - & - & - & - & - \\
\hline
\end{tabular}

Table 5: Water pricing effects on cropping pattern

\begin{tabular}{|c|c|c|c|c|c|c|c|c|}
\hline \multirow[b]{3}{*}{ Water pricing scenario } & \multirow[b]{3}{*}{ Base (ha) } & \multicolumn{3}{|c|}{ Cluster 2} & \multicolumn{4}{|c|}{ Cluster 3} \\
\hline & & \multicolumn{3}{|c|}{ Percentage change from base } & \multirow[b]{2}{*}{ Base (ha) } & \multicolumn{3}{|c|}{ Percentage change from base } \\
\hline & & W1 & W2 & W3 & & W1 & W2 & W3 \\
\hline Wheat & 156.0 & -4.0 & -8 & -8 & 41.0 & +0.1 & +0.3 & +0.3 \\
\hline RF-wheat & 1401.0 & +0.4 & +1 & +1 & 105.0 & +20.0 & +50.0 & +50.0 \\
\hline Barley & 18.0 & -18.0 & -35 & -35 & 69.0 & -10.0 & -54.0 & -54.0 \\
\hline RF-barley & 75.0 & +7.0 & +11 & +11 & 19.0 & +1.0 & +3.0 & +3.0 \\
\hline RF-chickpea & - & - & - & - & 4.5 & -100.0 & -100.0 & -100.0 \\
\hline Sugar beet & 17.0 & -100.0 & -100 & -100 & 44.0 & -21.0 & -23.0 & -23.0 \\
\hline Potato & 19.5 & -0.3 & -1 & -1 & 2.0 & 0.0 & 0.0 & 0.0 \\
\hline Onion & - & - & - & - & 5.5 & -1.0 & -2.5 & -2.5 \\
\hline Tomato & 45.0 & -3.0 & -9 & -9 & 55.0 & 0.0 & -2.0 & -2.0 \\
\hline
\end{tabular}

Water conservation: Water conservation is measured by the decreasing rate of demand for irrigation water after implementing a certain policy, as shown in Table 4. Water pricing policy works well in reducing the irrigation water use in the Mashhad plain when the water price level is high. Water pricing interventions result a reduction in demand for irrigation water up to $64 \%$. When the water price level is twice as much as current shadow price (W1), this policy would lead to a significant reduction in the quantity of water demanded by different group of farmers. The reduction mainly comes from Sugar beet, Potato and tomato. Since current low water prices for all farms coincided with high shadow prices, raising water price to $\mathrm{W} 1, \mathrm{~W} 2$ and W3 levels, lead to prices higher than current shadow prices and consequently result significant reduction in water demanded at farm level. Inputs tax will affect the cropping decision and hence the demand for irrigation water. However, until the price of $\mathrm{N}$-fertilizer increases up to $50 \%$, there are no appreciable changes in reduction of irrigation water use, especial in the case of 1 st and 4th RFs. When the $\mathrm{N}$-fertilizer tax increases by 25 and $50 \%$, the demand for irrigation water decreases by a similar percentage in the case of 2 nd and 3 rd RFs, while in the case of two other RFs irrigation water demand still remains fixed. In the fungicides tax scenario, changing the fungicides cost has similar impact on irrigation water demand as $\mathrm{N}$-fertilizer tax policy so that these two policies could be an alternative option for each other in reducing demand for irrigation water. Taxation on sugar beet and tomato production decreases irrigation water demand as expected. The main contributions to irrigation water reduction are from sugar beet and tomato. At the $25 \%$ tax rate, the demand for irrigation water falls by 13 and $5 \%$ in the case of RF (2) and (3), respectively. At this tax level, demand for irrigation water remains fixed in the case of two other RFs. Taxation on sugar beet lead to higher planted area of tomato and vice versa. Thus an effective output tax policy that follows irrigation water conservation must comprise taxation on both crops simultaneously. Altogether, Water pricing and output tax policies have more influence on water demand while input tax policy remains inefficient.

Land reallocation: The base cropping area for each crop (in hectare) and the percentage change from its base level are reported in Table 5. Since input and output taxation didn't have substantial effect on input's demand in the case of RF (1) and RF (4) and for simplicity, cropping pattern changes shown only for RF (2) and (3). The cropping area decreased for almost all major crops except rain-feed crops, as the price of water increased. Because of its high water requirement, sugar beet excludes from cropping pattern in the case of RF (2). When the W2 water pricing level implemented, the changes of cropping patterns are almost the same as at the W3 level. From the perspective of cropping patterns, the most affected crop is sugar beet which only uses less than 1 and $13 \%$ of the total irrigation 
water at the base level in the case of RF (2) and (3), respectively. The production of rain-feed crops, such as rain-feed wheat and rain-feed barely, increases up to $50 \%$ along with the increasing water price.

Social impact: Performing the cited scenarios would lead to changes in the employment, as shown in Table 6. The decrease in farm labor is a social impact caused by substitution of the most water intensive crops such as sugar beet, potato and tomato, which are normally also more labor-intensive, by others with reduced water and labor requirements. These changes in farm labor depend on the farmers' behavior and range from reduction by $16 \%$ in current labor demand (RF 3 for $\mathrm{O}_{2}$ scenario) to an increase by $0.24 \%$ (RF 3 for I2 scenario) in current labor demand. Farm operations in the study area are based on family labor with little hired labor. So, changes in demand for labor would basically be translated into changes in farmers' leisure. A slight change happens with demand for labor as the input tax policy implemented. There exist a variety of responses to other policies among different groups of farmers. So that output taxes, lead to lower employment level than water pricing policies. After performing a scenario, farmers change use of labor but after labor's redistribution, total employed labor remains fixed. Taxation on sugar beet causes transferring of labors to tomato production and vice versa. Consequently, total labor employed in farm remains unchanged.
Environmental impact: The introduction of irrigation water pricing and output taxation would also reduce Nfertilizer consumption, as shown in Table 7. Crops such as onion, tomato and sugar beet with high water requirements have higher requirements for $\mathrm{N}$-fertilizer and fungicides than others with lower irrigation needs. The results have shown that in the case of RFs 1 and 4, the system is basically stable and able to match most of the scenarios without any change in the total consumption of $\mathrm{N}$-fertilizer and fungicides. So Table 7 includes only environmental impacts in the case of RFs 2 and 3. As water price increases farmers with high rates of water utilization per hectare (RF 2 and RF 3), reduce consumption level of $\mathrm{N}$-fertilizer significantly, while others are not induced to change their $\mathrm{N}$-fertilizer consumption level. Again, the impact of different input tax policies on $\mathrm{N}$-fertilizer consumption appears to be negligible. Output taxation may increases the Nfertilizer consumption by some crops, but total Nfertilizer consumption remains fixed or decreases.

Although, fungicide accounts for a small portion of production cost, results shown that alternative policy options have noticeable effect on fungicide consumption and consequently are efficient policies for reducing usage of this input (Table 8). Sugar beet, potato and tomato have a much higher application rate of fungicide than other crops. Therefore a fungicide tax decreases the cropping area of these crops that finally results reduction in fungicide consumption.

Table 6: Changes in employment (\%)

\begin{tabular}{|c|c|c|c|c|c|c|c|c|c|c|c|}
\hline \multirow[b]{3}{*}{ Model No. } & & & & \multicolumn{4}{|c|}{ Input tax policy } & \multicolumn{4}{|c|}{ Output tax policy } \\
\hline & \multicolumn{3}{|c|}{ Water pricing policy } & \multicolumn{2}{|c|}{ n-fertilizer } & \multicolumn{2}{|c|}{ Fungicide } & \multicolumn{2}{|c|}{ Sugar beet } & \multicolumn{2}{|c|}{ Tomato } \\
\hline & Wl & W2 & W3 & I1 & $\mathrm{I} 2$ & I1 & $\mathrm{I} 2$ & $\mathrm{O} 1$ & $\mathrm{O} 2$ & $\mathrm{O} 1$ & $\mathrm{O} 2$ \\
\hline (1) & -1.40 & -1.40 & -1.4 & - & - & - & - & - & - & - & - \\
\hline (2) & -3.60 & -3.60 & -3.6 & -3.70 & -3.70 & -3.70 & -3.70 & -3.8 & -3.70 & -3.7 & -3.60 \\
\hline (3) & -2.80 & -11.80 & -5.4 & +0.30 & +0.27 & +0.27 & +0.24 & -6.0 & -9.60 & -9.3 & -16.00 \\
\hline (4) & -0.08 & -0.08 & -9.0 & -0.08 & -0.08 & - & - & -0.08 & -0.08 & - & -0.08 \\
\hline
\end{tabular}

Table 7: Reduction in N-fertilizer utilization (\%)

\begin{tabular}{|c|c|c|c|c|c|c|c|c|c|c|c|}
\hline \multirow[b]{3}{*}{ Model No. } & & & & \multicolumn{4}{|c|}{ Input tax policy } & \multicolumn{4}{|c|}{ Output tax policy } \\
\hline & \multicolumn{3}{|c|}{ Water pricing policy } & \multicolumn{2}{|c|}{$\mathrm{n}$-fertilizer } & \multicolumn{2}{|c|}{ Fungicide } & \multicolumn{2}{|c|}{ Sugar beet } & \multicolumn{2}{|c|}{ Tomato } \\
\hline & Wl & W2 & W3 & I1 & $\mathrm{I} 2$ & $\mathrm{I} 1$ & $\mathrm{I} 2$ & $\mathrm{O} 1$ & $\mathrm{O} 2$ & $\mathrm{O} 1$ & $\mathrm{O} 2$ \\
\hline$\overline{(2)}$ & 4.13 & 6.3 & 6.0 & 1.40 & 1.60 & 1.6 & 1.40 & 1.4 & 1.4 & 1.4 & 1.4 \\
\hline (3) & 5.80 & 11.8 & 12.2 & 0.11 & 0.14 & 0.1 & 0.11 & 4.5 & 8.3 & 2.6 & 4.8 \\
\hline
\end{tabular}

Table 8: Reduction in fungicide in different scenarios $(\%)$

\begin{tabular}{|c|c|c|c|c|c|c|c|c|c|c|c|}
\hline \multirow[b]{3}{*}{ Model No. } & & & & \multicolumn{4}{|c|}{ Input tax policy } & \multicolumn{4}{|c|}{ Output tax policy } \\
\hline & \multicolumn{3}{|c|}{ Water pricing policy } & \multicolumn{2}{|c|}{$\mathrm{n}$-fertilizer } & \multicolumn{2}{|c|}{ Fungicide } & \multicolumn{2}{|c|}{ Sugar beet } & \multicolumn{2}{|c|}{ Tomato } \\
\hline & Wl & W2 & W3 & I1 & $\mathrm{I} 2$ & I1 & $\mathrm{I} 2$ & $\mathrm{O} 1$ & $\mathrm{O} 2$ & O1 & $\mathrm{O} 2$ \\
\hline (2) & 5.5 & 10.0 & 10.0 & 1.02 & 1.10 & 1.00 & 1.03 & 0.3 & 0.3 & 4.0 & 6.9 \\
\hline (3) & 2.0 & 5.4 & 5.4 & 0.12 & 0.14 & 0.02 & 0.06 & 2.5 & 5.0 & 13.4 & 25.0 \\
\hline
\end{tabular}




\section{DISCUSSION}

This research intended to provide a better understanding of alternative irrigation policies compared to water pricing by examining irrigation policy options for the Mashhad plain in Iran. Two important conclusions can be drawn from this research. From the methodological point of view, is worth emphasizing the advantages of cluster analysis and PMP methods. Indeed, from the policy making point of view, water pricing policy performs more effective than input and output tax policy to reduce irrigation water demand and conserve water. The actual behavior patterns vary significantly when specific groups of irrigators (clusters) are studied.

By comparing the change from base level, the model results show that increasing irrigation water price has large effects on welfare at farm level while certain rates of input and output taxes can decrease the demand for irrigation water and welfare level a bit. In addition, input tax policy has small effects than water pricing and output tax policy scenarios on farmers' welfare. The input tax policy was not an effective policy in this study. In other words, N-fertilizer and fungicide are not a close complement to irrigation water. The comparisons also indicate that input taxes and output tax at higher level could be as an alternative option for water pricing. Taxation on sugar beet lead to higher planted area of tomato and vice versa. Output tax on tomato and sugar beet could be used to reduce irrigation water demand on these two crops. This would promote cultivation of less water intensive but profitable crops such as cereals. Cropping patterns changed appreciably for water pricing policies. While input tax and output tax policies were not effective in changing cropping pattern and had limited effects on the cropping pattern. Results indicate that cultivation of sugar beet, potato and tomato decrease more than less water intensive crops. Output taxes, lead to lower employment level than water pricing policies but a slight change happens with demand for labor as the input tax policy implemented. Impact of different input tax policies on $\mathrm{N}$-fertilizer consumption appears to be negligible.

\section{CONCLUSION}

Water pricing policy works well in reducing the irrigation water use when the water price level is high and will have, in most cases, higher effects than other policy scenarios. As water price increases farmers with low rates of water utilization per hectare reduce consumption level of $\mathrm{N}$-fertilizer significantly, while others are not induced to change their $\mathrm{N}$-fertilizer consumption level. Low level of input taxation should not be used if the policy goal is to limit irrigation water. A fungicide tax may not be a good driver in decreasing irrigation water demand and keeping the welfare level similar. Water pricing and output tax policies are better suited and effective than water complementary input factor taxation.

However, Policy scenario outcomes in reality will not be as smooth as in our results. It is worth remembering that achieving the positive impacts discussed here would require an appropriate legal and social framework. Since irrigation water in Iran historically and legally has been regarded as a common good and most farmers still believe that price of this resource should not increased, a slow evolution of farmers' mentality is required, in the direction of regarding water as an economic good and rising price of this scarce resource.

\section{REFERENCES}

1. Aldenderfer, M.F. and R.K. Blashfield, 1984. Cluster Analysis. Sage Publications. 1st Edn., Beverly Hills, USA., ISBN: 0803923767, pp: 88.

2. Asadi, H., G.R. Soltani and J. Torkamani, 2007. Pricing irrigation water in Iran, case study of areas under taleghan Dam (In Persian). Q. J. Agric. Econ. Develop., 58: 61-90.

http://www.agri-peri.ir/arshivefaslname/58.htm

3. Barkaoui, A. and J.P. Butault, 1999. Positive mathematical programming and cereals and oilseed supply within EU under agenda 2000. Proceeding of the 9th EAAE Congress on European Agriculture Facing The 21st Century in a Global Context, Aug. 24-28, Warsaw, pp: 1-25. http://ideas.repec.org/a/ags/aergaa/26452.html

4. Borimnejad, V. and GH.R. Peykani, 2005. Effect of improvement in agricultural irrigation yield on increasing irrigation water table. (in Persian). Q. J. Agric. Econ. Develop., 47: 69-94. http://www.agriperi.ir/arshivefaslname/47.htm

5. Buysse, J., G.V. Huylenbroeck, and L. Lauwers, 2007. Normative, positive and econometric mathematical programming as tools for incorporation of multifunctionality in agricultural policy modelling. Agric. Ecosyst. Environ., 120: 70-81. http://linkinghub.elsevier.com/retrieve/pii/S016788 0906003902

6. Chakravorty, U. and D. Zilberman, 2000. Introduction to the special issue on: Management of water resources for agriculture. Agric. Econ., 24: 3-7. http://ideas.repec.org/a/eee/agecon/v24y2000i1p37.html 
7. Day, R.H., 1963. On aggregating linear programming models of production. J. Farm Econ., 45: 797-813. http://www.jstor.org/stable/1235749

8. Ehsani, M., 2005. A vision on water resources situation, irrigation and agricultural production in Iran. Proceeding of the ICID 21st European Regional Conference 2005, Frankfurt (Oder) and Slubice, Germany and Poland, pp: 1-7.

http://www.zalf.de/icid/icid_erc2005/html/erc2005 pdf/topic_3/ehsani.pdf

9. G'mez-Limń, J.A. and L. Riesgo, 2004. Irrigation water pricing: Differential impacts on irrigated farms. Agric. Econ., 31: 47-66. http://ideas.repec.org/a/eee/agecon/v31y2004i1p47 $-66 . h t m l$

10. Graindorge, C., B.H. Frahan and R.E. Howitt, 2001. Analyzing the effects of agenda 2000 using a CES calibrated model of Belgian agriculture. Proceedings of the 65th EAAE Seminar on Agricultural Sector Modeling and Policy Information Systems, Mar. 29-31, Bonn, Vauk, pp: 177-186.

http://www.cababstractsplus.org/abstracts/Abstract. aspx?AcNo=20013047005

11. He, L., W.E. Tyner, R. Doukkali and G. Siam, 2005. Strategic policy options to improve irrigation water allocation efficiency: analysis on Egypt and Morocco. Paper presented at the American Agricultural Economics Association Annual Meeting, July 24-27, Providence, pp: 1-37. http://ideas.repec.org/p/ags/aaea05/19467.html

12. Heckelei, T. and W. Britz, 2000. Positive Mathematical Programming with Multiple Data Points: A Cross-Sectional Estimation Procedure. Cahiers d'economie et Sociologie Rurales, 57: 28-50. http://www.inra.fr/esr/publications/cahiers/pdf/hec kelei.pdf

13. Hossainzad, J. and H. Salami, 2004. Selecting production function for estimating economic value of agricultural water: Case study of wheat (In Persian). Q. J. Agric. Econ. Develop., 48: 53-84. http://www.agri-peri.ir/arshivefaslname/48.htm

14. Howitt, R.E., 1995. Positive mathematical programming. Am. J. Agric. Econ., 77: 329-342. http://www.jstor.org/stable/1243543

15. Howitt, R.E., 1995. A calibration method for agricultural economic production models. J. Agric. Econ., 46: 147-159.

http://ideas.repec.org/a/bla/jageco/v46y1995i2p147 $-159 . \mathrm{html}$
16. Judez, L., S. Chaya, S. Martinez and A.A. Gonzalez, 2001. Effects of the measures envisaged in 'agenda 2000 ' on arable crop producers and beef and veal producers: An application of positive mathematical programming to representative farms of a Spanish region. Agric. Syst., 64: 121-138. http://ideas.repec.org/a/eee/agisys/v67y2001i2p121 $-138 . h t m l$

17. Khalilian, S. and M. Zare, 2005. Valuing underground water for utilizing in agriculture, case study of wheat producers in Kerman Township (In Persian). Q. J. Agric. Econ. Develop., 51: 1-22. http://www.agri-peri.ir/arshivefaslname/51.htm

18. Konyar, K. and R.E. Howitt, 2000. The cost of the kyoto protocol to us crop production: Measuring crop price, regional acreage, welfare and input substitution effects. J. Agric. Resour. Econ., 25: 347-367. http://ideas.repec.org/a/ags/jlaare/30900.html

19. Konyar, K., 2001. Analysis assessing the role of us agriculture in reducing greenhouse gas emissions and generating additional environmental benefits. Ecol. Econ., 38: 85-103. http://ideas.repec.org/a/eee/ecolec/v38y2001i1p85103.html

20. Ministry of Jihad-E-Agriculture, 2006. Agricultural statistics yearbook 2006. Bureau of Information and Statistics. Iran. http://www1.agric.gov.ab.ca/\$department/deptdocs .nsf/all/sdd11863

21. Paris, Q. and R.E. Howitt, 1998. An Analysis of illposed production problems using maximum entropy. Am. J. Agric. Econ., 80: 124-138. http://www.jstor.org/stable/3180275

22. Paris, Q., 2001. Symmetric positive equilibrium problem: A framework for rationalizing economic behaviour with limited information. Am. J. Agric. Econ., 83: 1049-1061. http://www.jstor.org/stable/1244713

23. Perry, C.J., 2001. Charging for irrigation water: the issues and options, with a case study from Iran. Research Report 52. International Water Management Institute. Colombo, Sri Lanka. http://ideas.repec.org/p/iwt/rerpts/h027766.html 